This report was prepared as an account of work spousored by an agency of the United States employees, makes any warranty, express orernment nor any agency thereof, not any of thes bility for the accuracy, completeness, or userulied, or assumes any legal liability or responsiprocess disclosed, of represents that its use would of any information, apparatus, product, or ence berein to any specific commercio use would not inlringe privately owned rights Refer. manufacturer, or otherwise does not product, process, or service by trade name, trademart. mendation, of favoring by the United States Goventitute or imply its endorsement, recomand opinions of authors expressed herein to nevernment or any agency theroc?. The views United States Government or any agency thercof.

\title{
Joint Research and Development and Exchange of Technology on Toxic Material Emergency Response between LLNL and ENEA 1985 Progress Report
}

\author{
M. H. Dickerson, LLNL
}

R. Caracciolo, ENEA

Manuscript date: January 31, 1986

\section{LAWRENCE LIVERMORE NATIONAL LABORATORY University of California - Livermore, California - 94550}




\section{Acknowledgments}

This report is the product of material prepared by staff members from two projects: the Atmospheric Release Advisory Capability (LLNL) and the Accidental Release Impact Evaluation System (ENEA). The report is published in both ltalian and English languages. The authors wish to thank the following colleagucs for making this report possible: Pasquale Armenise, Giancarlo Boeri, Franco Desiato, Armando Guidoni (ENEA); and Paul Gudiksen. Rolf Lange. Kendall Peterson, and Thomas Sullivan (LLNL). 


\section{Contents}

Abstract .................................. . . 1

Introduction . . . . . . . . . . . . . . . . . . . . . . . 1

Progress During the Past 3 Years . . . . . . . . . . . . . . . . . . . . 2

Exchange Visits............................ 3

Technology Exchange ........................ . . . 4

New Objectives . . . . . . . . . . . . . . . . . . . . . . . . . 4 4

ARAC . . . . . . . . . . . . . . . . . . . . . . 4

ARIES . . . . . . . . . . . . . . . . . . . . . . 5

Present Status of Technology Exchange . . . . . . . . . . . . . . . . . 5

Model Research. . . . . . . . . . . . . . . . . . . . . . . . 5

Plume Rise . . . . . . . . . . . . . . . . . . . . . . 5

SPADE ............................ 5

ADPIC . . . . . . . . . . . . . .....6 6

Model Evaluation . . . . . . . . . . . . . . . . . . . . . 6

Soft ware Development . . . . . . . . . . . . . . . . . . . . . . . 7

ARAC General Philosophy . . . . . . . . . . . . . . . . . . . 7

ARIES General Philosophy . . . . . . . . . . . . . . . . . . . . . . T

Operational Models and Support . . . . . . . . . . . . . . . . . . 8

ARAC . . . . . . . . . . . . . . . . . . . 8

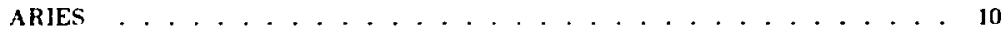

Cooperative Studies . . . . . . . . . . . . . . . . . . . . 14

Operational Models . . . . . . . . . . . . . . . . . . . . . . . . 14

System Design and Architecture . . . . . . . . . . . . . . . . . . . . 14

Data Retrieval and Decoding . . . . . . . . . . . . . . . . . 14

Graphical Display . . . . . . . . . . . . . . . . . . . . . . 44

Problem Monitor ... . . . . . . . . . . . . . . . . . . . . 14

Future Cooperation . . . . . . . . . . . . . . . . . . . . . . . 14

Model Resear.h. . . . . . . . . . . . . . . . . . . . . . 14

System Softwaje . . . . . . . . . . . . . . . . . . . . . . . 15

Operational Models . . . . . . . . . . . . . . . . . . . . 15

System Architecture. . . . . . . . . . . . . . . . . . . . . . . . . . . . . . 15

Meteorological Data Decoders . . . . . . . . . . . . . . . . 15

Graphical Displa, . . . . . . . . . . . . . . . . . . . . . . . 15

Communications . . . . . . . . . . . . . . . . . . . . . . . . 15

Hardware ........................... 15

Recommendations . . . . . . . . . . . . . . . . . . . . . . 17

Input/Output Standirdization ..................... . . 17

Model Development and Evaluation . . . . . . . . . . . . . . . . . . 17

Criteria for Emergency-Response Models . . . . . . . . . . . . . . . . . . . . . . 17

Emergency Response for Toxic Chemical Releases . . . . . . . . . . . . . . . . . 17

References............................... 19

Glossary . . . . . . . . . . . . . . . . . . . . . 21 


\title{
Joint Research and Development and Exchange of Technology on Toxic Material Emergency Response between LLNL and ENEA
}

\author{
1985 Progress Report
}

\begin{abstract}
For the past six years. the U.S. Department of Energy, LLXL, and the ENEA, Rome, Italy, have participated in cooperative studies for improving a systems approach to an emergency response following nuclear accidents. Technology exchange between LLNL and the ENEA was initially confined to the development, application, and evaluation of atmospheric 1ransport and diffusion models. With the emergence of compatible hardware configurations between LLXI and EXEA. exchanges of technology and ideas for inproving the development and implementation of systems are beginning to emerge. This report describes couperative work that has occurred during the past three years. the present state of each system. and recommendations for future exchanges of technology.
\end{abstract}

\section{Introduction}

Since 1980, the I'.S. Department of En"rgy (DOE). Lawrence Livermore National Laboratory (LLNL), and the Italian Cornitalo Nazionalc per la Ricerca e lo Sviluppo dell'Energia Nucleare e delic Encrgic Alternative (It alian Commission for Nuclear and Alternative Fuergy Sources. also known as ENEA). Rome. It aly. have engaged in cooperative studies. These studies provide real-time guidance to emergency response managers for atmospheric releases of nuclear mat erial.

During the past 13 years, LLNL has deve'uped the At mospheric Release Advisory Capability (ARAC) for the DOE to provide emergency planning, response, and assessment capabilities for atmospheric releases of nuclear material. An expansion phase that includes L.S. Department of Defense (DOD) facilities capable of handling nuclesi material is presently nearing completion. ${ }^{1}$ The ARAC service has responded to over 150 incidents and participated in major exercises during the past 11 years.

ENEA has developed a system similar to ARAC that is called the Accidental Release Im- pact Evaluation System (ARIES). The ARJFS sysiem has been used extensively for exercise Fianning and participation over the past three years. ARIES has recently moved to a new facility and insialled a new romputer system. ${ }^{2}$

Both the ARAC and the ARIES systems use the LLYL-dereloped MATHEW;ADPIC (M A) models ${ }^{3.4}$ as their major emergencyresponse models. These models were transferred to the ARIES system in 1981 and have formed the basis for cooperative research and developmert and exchange of technology between LLNL and ENEA. A joint report, ${ }^{5}$ publish $d$ in 1982. summarized the results of these exchanges for the first two years and described plans for the future.

The present report discusses the progress for both systems since 1982 , the present status of model research and soltware development, and plans for future cooperative studies. $A$ list of acronyms, symbols, and key words appears at the end of this report. 


\section{Progress During the Past 3 Years}

Since 1982, the ARAC service has expanded its hardware, software, and number of staff members to meet new commitments for emergency planning, response, and assessment. A major. new commitment is being made to the DOD for its nuclear-capable facilit ces localed in the L.S. Other nevi commitments include a closer tie to the U.S. Nuclear Regulatory Commission (XRC) for assistance in response to nuclear power plant accidents and to severa) states for possible nuclear accidents that might occur within their borders. At present, approximately 50 DOE and DOD facilities directly receive the $A R A C$ service using a partially automated system. Xew rapabilities have been developed by installing small computers to transfer data between nuclear facilities and the ARAC center. Expansion of the ARAC operational service by October, 1986 will provide continuing service to on-line sites and to U.S. agencies responsible for the health and safety of nearby populations. ${ }^{1}$ Figure I shows the operations room of the new AHAC center. The computers and associated hardware are located in an adjacent area.

The ARIES projert. started at the begirning of 1980 with cooperation from LLNL, quickly reached many of its goals. ${ }^{2}$ From 1983 to 1985 the system moved from a develop- mental to an operational phase. During this time, efforts were forused on ensuring that ARIES software and hardware were similar to that of the ARAC systern to maximize cooperation between the two organizations. For example, when ARAC incorporated Digital Equipment Corporation (DEC) VAX computers to run the system. ENEA made the same decision. In particular. ENEA acquired a VAX 11/782 computer and transferred all software to this system. The complete VAXcompatible codes, MATHEW:ADPIC (M/A), were received from LL.NL. Furthermore, an intermediate-level code, SPADE, was developed on the ARIES VAX system to describe wind-field and pollutant transport with a lagrangian puff model.

ARIES currently services three nuclea: power plants and several nuclear research facilities and will be able to service new power plants now under construction. The ARIES operations center is shown in Figure 2.

The Italian Emergency Coordination Center (ECC) recently issued a directive requiring an environmental impact statement, including accident and emergency preparedness analysis, for large ltalian industrial installations that have a potential for toxic chemical releases. The ltalian Civil Defense Ministry

Figure 1. ARAC operations center.

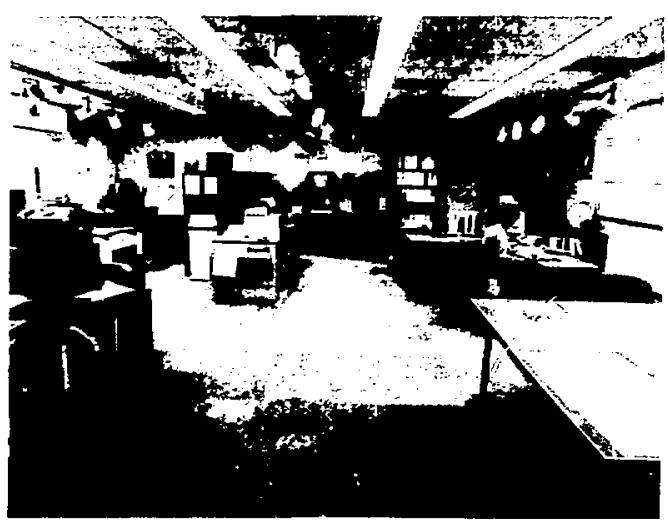




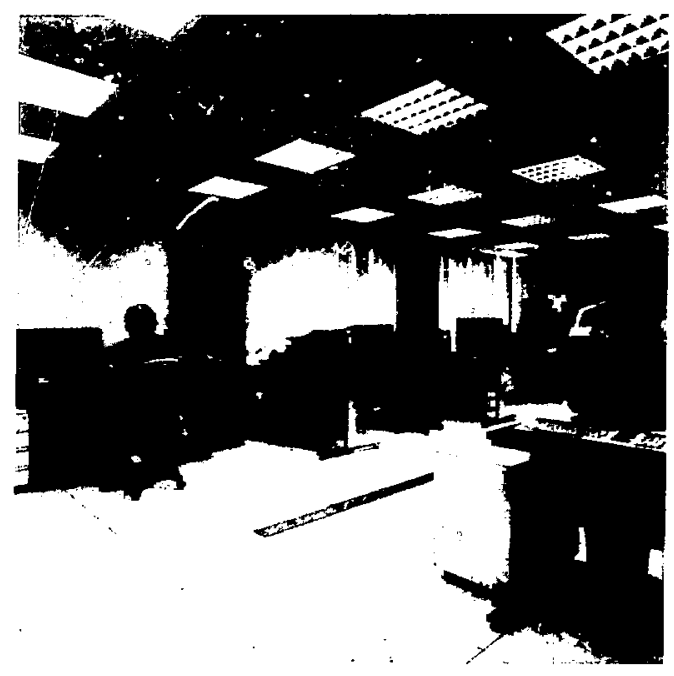

Figure 2. ARIES operations center.

asked the Directorate for Nuclear Safety and Health Protection (DISP) to supply technical support during acridents involving conventional toxir releases. DISP recently responded by starting an active program to make ARJES available in case of such accidents.

\section{Exchange Visits}

In 1983, four staff members from LLNL visited ENEA for 8 days to participate in an ENEA-sponsored international semirar and to plan for a continuation of the technology exchange program. The visit included observation of a field experiment conducted at a coast.al nuclear reactor site at Montalto di Castro, located approximately $100 \mathrm{~km}$ northwest of Rome. The goal of this investigation was to release atmospheric tracers and to measure the downwind tracer concentrations and meteorological parameters under sea-breeze conditions. Meteorological and uracer data were collected for subsequent evaluations of models. The results of this work are now part of the total $M / A$ evaluation data base.
The int ernational seminar included presentations and discussions relating the role of realtime diffusion models in emergency response to accidental releases. Representatives from eight countries participated in the discussions, which focused on the use of transport and diffusion models and the associated support required for a real-time response. The systems presented at the seminar provided an opportunity to discuss the merits and shortcomings of a spectrum of capabilities involving both simple and complex models.

During 1984, the ENEA sent Dr. Franco Desiato to LLNL for 2 months to work in a plume-rise module for the ADPIC code. Both organizations perceived the need for this capability. Dr. Desiato's visit provided an opportunity to develop this module and to share emergency response work that is ongoing at LLNL and ENEA. In addition, Dr. Desiato presented a seminar to the LLNL staff on the Montalto sea-breeze experiment.

In the spring of 1985 , Dr. Desiato and Dr. Pasquale Armenise (ENEA) visited LLNL for 2 weeks. The ENEA ARIES system was 
installed on the ARAC computers and demonstrated to the ARAC stafi. The completed portion of the expanded ARAC system was also demonstrated to the ENEA staff. The demonstrations and resulting discussions led to further technology exchange through the sharing of application software. The model evaluation work by ENEA on the Montalto seabreeze data set was also discussed for both the $M / A$ and the ENEA sequential-puff model, SPADE. Several methodologies for comparing model calculations with tracer measurements were reviewed. and plans were made for additional work. A jointly outlined paper, discussing the results of this research, was presented at the 1985 international conference in Luxembourg. ${ }^{\circ}$ A draft of a paper, based on development of a plume-rise module for $\mathbf{M} / \mathbf{A}$, was completed. ${ }^{7}$

In the spring of 1985 , Dr. Marvin Dick"rson (LLNL) visiced the ENEA for 1 week. Both an abstract and a paper discussing errergency response modeling from the user's point of view was jointly prepared for presentation at the Luxembourg conference, ${ }^{8}$ and the EXEA demonstrated their latest version of the ARIES system. Progress on cooperative efforts was summarized with emphasis on the modeling aspects, and each organization concluded that progress in system development efforts made future terhnology exchange in this area feasihle. Finally, the outline for the present report was developed.

In the fall of 1985, Dr. Rolf Lange (LLNL) visited ENEA to compare the Montalto seabreeze experimental results with the ARIES and ARAC nested-grid $M / A$ model calculations. Inrestigations of decoupling vertical and horizontal diffiusion coefficients using the seabreeze data set showed improved comparisons between model and measured cancentration values. The results were presented at the 1985 ]AEA international symposium in Rome. ${ }^{9}$

\section{Technology Exchange}

The major area of technology exchange between ENEA and LLNL during the past three years is model improvement and evaluation. LLNL evaluat ed the $M / A$ models against meteorological and tracer data measured in complex terrain. ${ }^{10}$ rolling terrain. 11 and emissions from a tall stack in flat terrain. ${ }^{12}$ These studies led to model improvements that, in turn, fed back to the operational models used by the ARAC and ARIES systems.

The E.XEA used sea-breeze data obtained at the Montalto site to evaluate a simpler model, SPADE: ${ }^{6}$ as well as their version of the M1/A models. Evaluation statistics produced by these studies were included in the overall statistical data base for these models. A summary of model evaluation studies performed for the $\mathrm{M} / \mathrm{A}$ models was recently presented to an IAEA sponscred international symposium. ${ }^{13}$

Technology exchange in the system area has lagged behind that in the modeling area: however, efforts have been macie to ensure that the two systems are nearly compatible so that future exchange of software and ideas can be readily accomplished. Once the basic expansions are completed, cooperative work in this area can proceed.

\section{New Objectives}

\section{ARAC}

The ARAC service is expected to complete its automated system by October 1986, when approximately 50 DOE and DOD sites will receive the service using the fully automated systern. The service will continue to be available to the NRC for nuclear power plant incidents and to other government agencies responsible for managing emergency response activilies associated with the transportation of nuclear materials. For example, ARAC provides guidance to the L.S. Federal Aviation Administration (FAA) in the event that a country tests nuclear weapons in the atmosphere. ARAC provides estimates of potential doses to passengers and crews of U.S. aircraft flying in or near the nuclear debris cloud. Should the estimated dose along the planned route exceed radiation guidelines, the flight path of the aircraft is modified.

ARAC will soon begin a feasibility analysis for response to toxic chemical releases. The fundamental principles of response to a nuclear accident are transferable to situations involving chemical accidents; however, response 
for toxic chemicals can be much more complex than these for nuclear releases. Thousands of chemicals pose a risk: many have unknown health effects. Futhermore, the frequency and variety of accidents involving toxic chemicals are much higher than those involving nuclear material.

Development of a hydrodynamic model to produce wind fields for nuclear facilities located in areas of complex terrain and meteorology is a long-term ARAC research project. The injtial objective is to model wind-field patterns under a given sel of boundary conditions. Output from such a model will be used to assess the consequences of a potential accident. This first-generation model is not expecied to provide assessments in real time, but implemer:tation of an advanced, real-time hydrodynamic model is feasible in the fuiture.

\section{ARIES}

The firs oojective for ARiES is to fully automale the sysion by rompleting the comunication network. Site data are presently collected at the central facility by a standard commerrial-grade voice line. Next, resources will be used to improve both the capabinitj and the system manageability of both the central and site facilities. Expansion of the system to handle accidental releases of conventional toxic material will be initiated. The mpansion is a substantial undertaking that will require a gradual extension of present capabilities, concentrating initially on the most important response aspects and the hiost toxic hemicals. Finally, field experiments will be conducted to improve model parameters for sea-brecze and calm wind conditions.

Many of the activities planned for the near future will be conducted in cooperation with LLNL. The development of some modules of the system or the investigations and testing of the models will be performed separately. Information will be exchanged either through writlen reports or visits. The main cooperative studies will be in the areas of model development and evaluation and of system software development. In particular. the following subjects will be treated:

- Decoupling of vertical and horizontal source-particle diffusion parameters in ADPIC.

- Model evaluation using field data.

- Plume rise module.

- Description for vertical wind profile in the absence of upper-air data.

- Development of SPADE model.

- Diffusion in calm wind conditions.

- Diffusion of conventional toxic materials.

- Optimization of codes.

- Management of meteorological data.

- Management of radiological data.

- Graphical analysis.

- Telephone connection between ARAC and ARIES central facilities.

- System software architecture.

\section{Present Status of Technology Exchange}

\section{Model Resenrch}

Extensive model research by L.LNL and ENEA has been an ongoing and cooperative effort for the past five years. The following paragraphss summarize the major research conducted during the past three years, since the last progress report, ${ }^{5}$ was issued.

\section{Plume Rise}

A prescription of plume-rise trajectory as a function of time was developed for ADPIC. This research covers momentum and buoyancy for vertical and bent-over plumes in a stable, neutral, or convective almospheric boundary layer. A draft report describing this work has been completed. ${ }^{i}$

\section{SPADE}

A sequential puff model of intermediate complexit; has been developed during the last two years and introduced into the ARIES system. Sequential Puff for Atmospheric Diffusion Evaluation (SPADE) provides a realtime, fast-response assessment for accidenta] 
release of nuclear material from a nuclear power plant into the atmosphere. SPADE is a 3-dimensional, Lagrangian, short-range puff model: effects of topography are not included. and it requires only simple meteorological and geographical data. SPADE has been recently evaluated with the meteorological and tracer data collected during the diffusion experiments in June 1983 and 1984 at Montalto di Castro.

SPADE was developed on the original ARIES computer system. In 1985, a neu version of the model was implemented on the ENEA VAX computer. New techniques for determining puff trajectories and a time- and space-interpolated wind-speed calculation were installed.

\section{ADPIC}

A time-smoothed, particle-generation process was introduced into the LLNL and ENEA ADPIC models to improve the near-source distribution of the plume. Improved resolution of the concentration pattern was obtained with the introduction of a nested grid close to the source and an interpolation algoritbm in the outer regions. This nested grid process, involving four successively smaller grids nested within the ADPIC grid, improves the accuracy of concentration resolution near the source by a factor of 16.

Input variables with averaging times different from those of the mean wind field (e.g., source term, rain rate, atmosp. eric stability, mixing-layer height) were separated in the ARIES version of $M / A$ and listed in a new ADPIC input file (PICIN1) that can be read at time intervals different from the wind fields (WINDY). Improvements were also made in ARIES output graphics. During the execution of ADPJC, the plume shape and direction, updated at each time step, are displayed over site geography on a video terminal.

At LLNL, versions of the ADPIC and plotling codes were programmed for both the CDC 7600 and VAX computers. Such programming was the first step in generating a single master version of the ARAC models, thereby simplifying development and evaluation of codes.
Other improvements for the LLNL M/A codes since 1982 include a multiple vertical wind-profile input for MATHEW. improved curves for the vertical diffusion coefficient $K_{z}$ that are based on similarity theory and validation tests, improsed surface-air concentration boundary condition in ADPIC, and expansion of the friction velocity $U$. calculation in ADPIC: to a 2-dimensional array that represents the iocal winds and terrain. Some of these model improvements were shared by EXEA and LLVI..

\section{Model Evaluation}

The Montalto sea-breeze data sets collected by ENEA and Centro Comune di Ricerca (CCR) in 1983 and 1984 were used to evaluate $M / A$. Several continuous tracers released under sea-breeze conditions at the Montalto nuclear plant site were modeled by both ENEA and LLNL. Results of these studies were reported at the $1985 \mathrm{IAEA}$ conference in Rome. ${ }^{9.13}$

Extensive $\mathrm{M} / \mathrm{A}$ validation studies were conducted by LLNL on the ASCO'T-Geysers (drainage flows), MATS, and EPRI (tal! stark) data sets. ASCOT refers to the DOE program on Atmospheric Studies in Complex Terrain; MATS refers to the Mesoscale Atmospheric Transport Studies; FPRI is the Electric Power Research Institute (L.S.). These studies were presented at the DOE AMS Model Validation Workshop in Ortober 1984 on $\mathrm{Ki}$ awah Jsland, South Carolina, ${ }^{1012}$ and at the American Meteorological Society (A.MS) Conference on Mountain Meceorology in Octuber 1984 in Portland, Oregon. ${ }^{14}$ These evaluation studies illustrated weaknesses in standard regression analysis when individual scenarios are modeled, and LLNL and ENEA developed optional statistical packages to judge the effectiveness of models. One of the procedures computes the percentage of cases in whicb measured and computed concentrations agree to within in a factor $R$. Another technique compares agreement within some specified angular uncertainty. These methods will be tested in future studies. 


\section{Software Development}

\section{ARAC General Philosophy}

The major goal for the new ARAC system was to improve response effectiveness by means of the following specifications:

- Transmission of preliminary calculations and graphics to a site within $\mathbf{1 5}$ minutes after initial notification.

- Completion of sophisticated calculations withis 45 minutes and every hour thereafter until the release is terminated.

- Capability of handling up to three emergencies simultaneously.

- Twenty-four hour per day support by a staff of highly trained emergency-response persomnel.

- Support of up to 100 remote site systems.

- Rapid response to accidents at arbitrary locations where no site computer system is available.

Support for remote sites was designed in the form of a small computer system. The computer enables sites to communicate with the ARAC central facility. to display products generated at the central facili y, to manage loca! meteorological data, and to graphically display rosults from a simple atmospheric dispersion model continuously and automatically.

Backups in hardware, software, sources of meteorological data, and product delivery syslems were designed to ensure that the new sysLem could recover and respond despite hardware or software failures. In addition, the new system requires minima! interaction among operators ano meteorologists at the central facility and personnel at the site racility. Modern programming practices were used to develop a modular system that has clearer interfaces to facilitate integration of enhancements and to reduce the cost of maintenance.

To save time and iacrease confidence in the calculations, h:ıman intervention focuses on quality assurance. All meteorological data are automatically validated, and both questionable and fatal input values are Hagged. Historical plots of meteorological data at all stations are used so that a meteorologist or assessor car as- sess the reasonableness of a given observation. A 3-dimensional graphics display for terrain is cur.ntly under development. ${ }^{15.16}$

To notify the meteorologist of hardware and software problems. extensive errordetection routines are built into the system. Error messages generated by the site system are formatted into operator messages and sent to the central system. Interactive and automated processes inform the meteorologist of error 5 . In addition. all information (including messages) relating to a problem is archived to facilitate post-assessment studies.

Human engireering factors (ergonomics) were given careful consideration. Menus and forms for both site and central systems are tailored to a user's level of expertise. For example, certain forms aie designed to guide the site user in data entry, while more fexible forms are designed for ARAC personnel.

\section{ARIES Genezal Philosophy}

Recent structural modifications have been made in the ARIES hardware and soft ware architecture. A DEC VAX 11,/82 multiprocessor computer system has been dedicated to execute the system software. The increase in computational power and the need to improve system performance (especially when the ARIES staff is not immediately alerted to a problem) stimulated conversion of the software architecture from sequential to concurrent. At present the ARIES system is a virtually distributed system and consists of several different processes that share the two processors in the computer system. Furthermore, the main programs METEO, MEDIC. MATHEW, and ADPIC, as well as some other minor programs, are assembled into a pipeline architecture so that the output of one or more components is the input for another component.

All ARIES programs can be divided in two groups: either functional programs or programs for supervision and control. Those programs that directly relate to the system's finaì goals, e.g., codes describing wind fields and pollutant dispersion, are functional programs. Other programs that supervise and control the 
whole system, such as MONITOR and SUPERVISOR, are in the second group. As a consequence of changes in hardware architecture, other structi!ral modifications in the software archilecture are made to improve system performance and to obtain greater reliability.

\section{Operational Models and Support}

Operational models are directly integrated in to the ARAC and ARIES systems, whereas research models are used to develop improvements. In a carefully constructed set of procedures, improvements made in the research models are tested and may be periodically transferred to the operational mode's.

\section{ARAC}

Models. Several computer models are available to ARAC for simulation or estimation of the consequences of an atmospheric release of hazardous material on a local, regional, or global scale. Local assessments (within about 10 to $20 \mathrm{~km}$ from a source) and regional assessments (within about $100 \mathrm{~km}$ from a source) are performed with 3-dimensional $\mathbf{M}$ / $\mathbf{A}$ codes to estimate air concentrations, integrated doses, and ground contamination arising from continuous or instantaneous releases from point sources. Effects of stratified shear flows, calm conditio: $:$, topography, deposition, radioactive decay, and particulates can all be treated with the codes.

The KDFOC2 model $^{17}$ can be used for assessment of radioactive fallout, and the 2BPUFF and PATRIC models can be used for long-range transport and diffusion from nuclear explosions. ${ }^{18,19}$ PATRIC is a coarse-resclution derivative of ADPIC, adapted to operate with hemispheric-scale wind fields to calculate the intercontinental transport and diffusion of material.

Model Parameters. Several aids ere under development to help the meteorologist in selecting model parameters. These aids offer the meteorologist a choice of values.
- Default values including those that are site-specific.

- Automatically romputed values.

- On-line data bases.

- On-line help information.

Problem-specific information. such as location and time of the release. substances involved, and whether the release is in the form of a puff or a plume, is entered into an on-line questionnaire at the central facility or on a site system and then accessed by the computer models.

Site-specific geographical maps ere displayed in the questionnaire for supported locations. To specify the release coordinates, the user positions a cursor at the reported location. Site maps are also used for interactive selection of the model grid. Parameter values are estimated automatically by software on the basis of available meteorological data and information contained in the questionnaire. The meteorologist can modify these values interac ively by choosing algorithms, using default values, or entering values directly.

Information about potential accident/release sites, the half-life of various radionuclides, and dose-conversion factors for several exposure pathways is stored on-line fo: interactive use. On-line information to document procedures and to aid in decision-making is available throughout the system to help the meteorologist interact with the computer.

Meteorological Data Collection. The system has numerous attomated capabilities that are initiated by the software when corresponding information is entered in the questionnaire. As soon as a release time is recorded on the question meteorological data collection are initiated for stations within the default radius of the release. Meteorological data for the location and duration of a release are collected in real time for input to the models. Most meteorological data for these models come from the U.S. Air Force Global Weather Central (AFGWC), which provides a worldwide master station catalog of all stations that report meteorological data to the World Meteorological Organization (WMO). For hourly calculations, the system 
typically collects the necessary meteorological data by 20 minutes after the hour.

Data Bases. The standard regional-terrain file for ARAC emergencies consists of a square that is $200 \mathrm{~km}$ on a side oriented on a Lniversal Transverse Mercator (UTM) grid with a resolution of $0.5 \mathrm{~km}$. The data base created specifically for ARAC emergencies is composed of files that are also terrain grids at $0.5-\mathrm{km}$ resolution that co- er a 120-km square area oriented on a UTM grid. ${ }^{15}$ The system allows a file to cover any I-deg quadrangle on the Earth. One terrain grid jc a vailable for each I-deg quadrangle in the ontinental L.S. The southwest corner of each quadrangle is approximately $5 \mathrm{~km}$ north and $5 \mathrm{~km}$ east of the southwest corner of each terrain grid. The approach provides significant overlap with adjacent files. The system can arcess and create a terrain data file for any point in the $\mathrm{I} . \mathrm{S}$. in real time within about 2 minutes.

Base Mapping. In addition co trrrain data, ARAC also requires the fast generation of base map geography for any region. Such data are used as an overlay for the graphic products distributed to users of the ARAC service to orient the contours with iespect to the region's geography. At present, this capability is limited. Information is digitized from various maps using the L.S. Geological Surve' (LSGS) 1:250 000 topographic maps as a base and supplementing them with detailed maps provided by each supported site. The process for preparing for an incident away from a supported site is time-consuming. A geographic data base using 1:2000 000 mapping provided by t'ue USGS will soon be installed.

Graphics. Quality contro ${ }^{2}$ of terrain data is of the utmost importance. Corrupted data can appear at any point in the process of creating terrain data for the models. The key to quality assurance is graphical display of the terrain. Since the terrain system became operational, standard procedure has been to contour the regional terrain file as soon as it is produced. Interactive manipulation of small amounts of data permits recovery from certain types of problems. Future efforts will be directed to- ward the development of additional techniques for recovering from losses of larger amounts of data.

A new graphics product now operational on ARAC VAX computers is an overhead view of a shaded-relief ir. age of thr terrain surface. This product uses color to provide an exceptionally clear rendering of the Farth's surface in which feat ures are distinct and recognizable. it clearly highlights any problems in the data, even at the individual grid-cell level. A blackand-white example of terrain displayed by this system is shown in Figure 3.

Communicotions. A supcrior electronic communications systen is of primary impor. tance in a distributed anplication, such as ARAC, for which hardware components may be remotely located from the central system. Early in the project, it was apparent that the VAX hardware could not handle remote communications problems. DDCMP, a DEC standard protocol, was chosen to communicate with the remole site systems via LSI $11 / 23$ communications front-end processors and the PC350 site system.

This communications system marlages the transfer of messages and files among the ARAC central romputers and the individual site compuiers. The DDCMP system will replace the present terminal line system that requests and receives worlduide meteorological data rrom the AFGWC. It will also obtain meteorological data from the site meteorolegical towers by mrans of the site-system computers.

Remote Site System. Site computer users can initiate a response at the central facility by entering source-term information into an on-line questionnaire. The site computers can also use the system to collect meteorological data from on-site towers, enter on-line supplementary meteorological observations obtained from local (sometimes portablc) instruments, provide two-way communication with the central facility, prepare simple dispersion model calculations, and graphically display both these models and the ADPIC froducts prepared at the central facility. ARAC microprocessorcontrolled meteorological towers se used to collect and archive observations continuously. 
Figure 3. Computer generated terrain for a 40- $\times 40-\mathrm{km}$ area surrounding the TMI-2 nuclear power plant site.

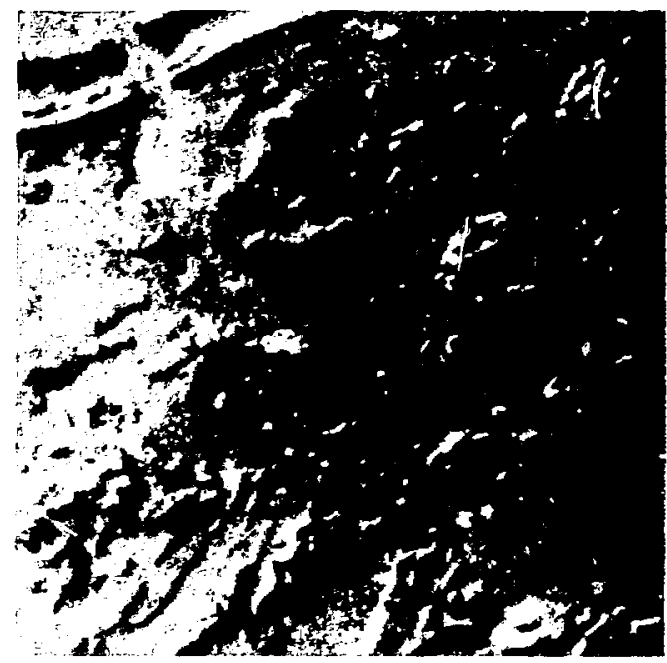

These tcwers are accessible to both the sile and the ARAC certral computer systems.

Hardware. The basic hardware configuration used by ARAC is shown in Figure 4. Hardware at the central facility consists of a cluster of two DEC VAX 11/782 computers that use three DF C LS! $11 / 23$ computers, connected via Ethernet, as communications front-end processors. This system has $\sim 2.7$ Gigabytes of disk storage including 1.2 Gigabytes in a sharcd disk form. DEC PC350 computers and meteorological towers with Handar 540 inicroprocessors are used as the site system at ARACsupported facilities. Connection to the ARAC central facility is via standard phone link used on an as-required basis. A Xerox 495 telecopier connected to the VAX computers permits direct transmission of text messages. Planned development of a graphics driver will allow the central facility to transmit VAX-produced graphics directly to semote telecopiers at both supported and nonsupported sites. A voicesynthesized, page-alarm system with micropro- cessor is used to alert emergent, - -response personnel.

\section{ARIES}

Mode]g. Two categories of operational models are presently being used by ARIES. The fist are those models used to describe pollutant transport. At present ARIES uses the M/A complex models or the SPADE model. The second type of model is used to evaluate health effects, environmental contamination, and countermeasures in the event of inadvertent release of toxic material.

Meteorological Data Collection. The ARIES center receives meteorological data from the Italian Weather Service via a dicatrd phone line. All meteorological messages for a 48-hour period are stored on disk files by an IBM/Series 1 computer. On the same computer, METEO software allows the user to select desired data, deperding on the site and time of an accident. At present, the output 


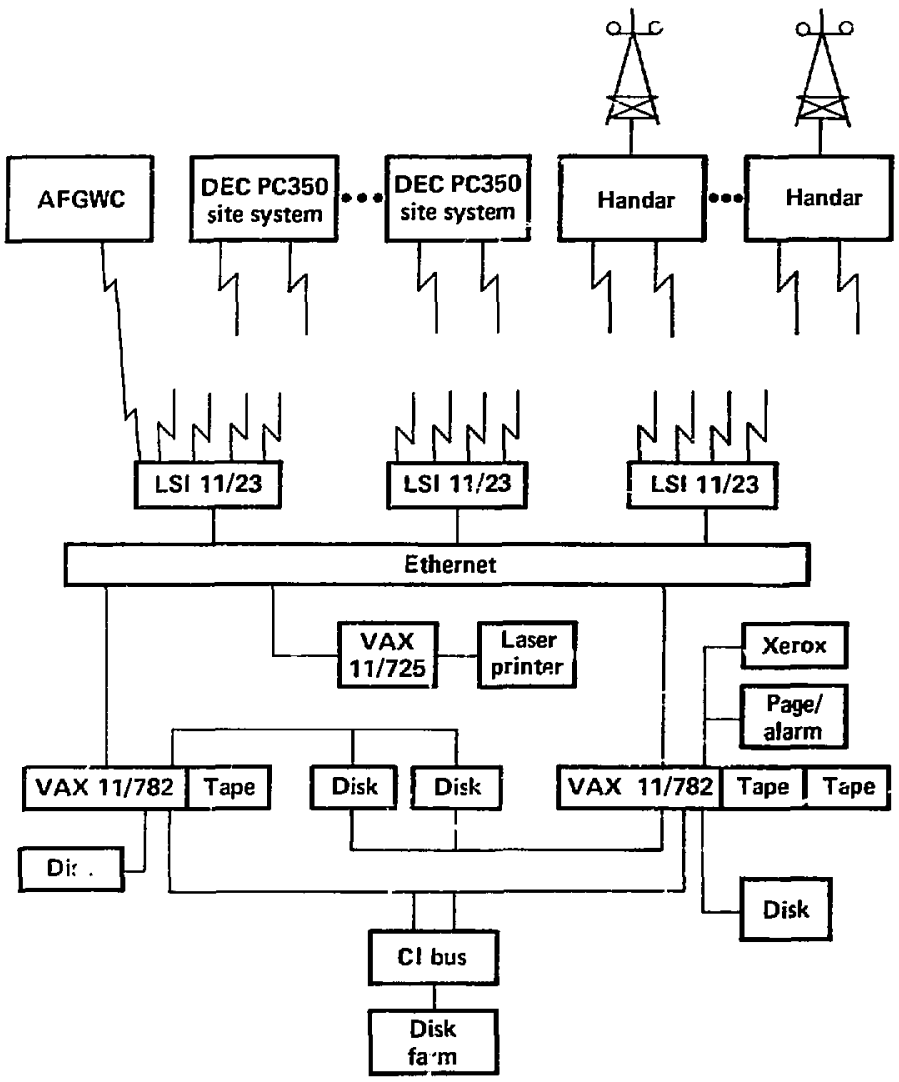

Figure 4. ARAC present hardware configuration.

of METEO is a printout of SYNOP decoded data and of METAR, T'EMP, and PILOT undecoded data. Another program uses available SYNOP wind data to provide the streamlines in the region of interest and to calculate the best location of the $\mathrm{M} / \mathrm{A}$ grid.

Data Bases. Data-base and management systems that allow for the rapid extraction of pertinent information needed during an emergency are an essential part of the ARIES sys- tem. This component of the system was developed during construction of plant siting maps that were used to select the most suitable areas in Italy for nuclear power plants. Moreover, several integrations and improvements have been made regarding the quality, quantity, and spatial resolution of territorial parameters. Territorial variables that are presently available are:

- National, regional, provincial, and communal borders. 
- Contours of cities, towns, and vilages with $\mathbf{2 0 0}$ or more inhabitants.

- Demography (population of each center).

- Roads, highways, and railroads.

- Airports.

- Meteorological towers.

- Rivers, lakes, and watersheds.

- Seismic occurrences.

- Isolines of seismic activity and volcancs.

- Topography (average heights of 250- $x$ 250-m cells).

Graphics, Graphics software now in use to obtain color displays of output from the ARIES system is the Tektronix Interactive Graphics Library (IGL-TEX) and CALCOMP graphic packages. Output devices use Tektronix color graphic terminals and a Versatec electrostatic printer-plntter. The main components of the graphic software are:

- Interartive graphics to modify certain input pirrameters such as topography and wind profiles, when necessary.

- Graphics monitor to display the transport of the plume at each time step of the calculation.

- Standard graphics to display at 0.5- or 1-hour intervals the graphical representation of the analysis, e.g., wind field, concentration, and dose contours.

- Analysis of system events to display at selected times diferent sections and concentration contours.

Communications. The effective operation of the ARIES system is strongly dependent on rapid data exchange among the central facility, site facilities, local response centers, and other agencies involved in an emergency. The ARIES network is characterized by a "star" topology in which the ARIES Central Facility (ACF) is located in the central node. Peripheral nodes are, in general, connected to $\mathbf{A C F}$ by means of both voice (authorities rooms) and data phone lines. Other data are collected at the ACF by two radio receivers connected to the European Weather Centers and to Meteosat 2 (the ESA meteorological satellite). The three main nodes or groups of nodes linked by data phone lines are CNMCA (sometimes called SMA, which is the Italian Weather Center), sites, and the Mobile Laboratory.

CNMCA transmits to the ACF meteoralogical observations from national and international surface and upper-air stations and forecasts for 6 to 96 hours. At present. the telephone line connects the CNMCA-IBM 5,370 computer to the ARIES-I9M S, 1 minicomputer. Soon meteorological data will be collected at the ACF directly onio the VAX by means of the DEC DLP1l synchronous communication interface and the DEC PE 3271 program emulator.

Remote Site System. In Italy, site facilities are generally located at ome distance from nuclear installations. The utilities are responsible for collecting and transmittis:g sourceterm, meteorological, and radiological data to authorities engaged in the management of an emergency. Analysis of an accident is performed by a local committec, which includes ENEA-DISP personnel. and by the staff of the ENE $\backslash$ Emergency Center, 1, siading the ACF. This arrangement requires the ARIES network to have two lir.ks from the ACF: one to the local response center ar: $\mathcal{J}$ another to the nuclear power plant to collect onvironmental data. $\mathrm{Ar}_{3}$ other link, not included in the ARIE 3 network, connects the nuclear power plant to the local response cerstar. Because of current difficulties in obtaining dedicated phone lines for data communications, these nodes (sites) are connected to the ACF by means of commercial lines. Fully automated data links are planned for the beginning of 1986 .

As previously mentioned, ARIES has two different site systems at the nuclear power plants: one dedicated to data collection and another used for accident analysis. The second system is similar to the ARAC Site Facility and is located near the installation. This remote systert: automatically collects data and has the capability of performing an analysis of the accident. It is equipped with a minicomputer for data management and for executing simple atmospheric dispersion codes. Recently, ARIES installed the SPADE model on a minicomputer similar to the one used as a remote system. 
At research installations, many of which are ENEA research centers, tine two functions of data collection and analysis are performed by one system, usually located at the plant emergency center.

Hardwane. The ACF basic hardware configur:ation is shown in Figure 5. ARIES hardware consists of a DEC VAX I1/782 computer, an IBM Series/1 minicomputer used as a communications front-end processor, and several management components, e.g., system consoles, METEO facility, and graphics anal- ysis. Each component consists of one or more input/output devices. The most complex device is the system console equipped with:

- A terminal for input of data (e.g., WINDY, TOPIN, MINVF, and PICIN).

- A terminal that monitors and displays the main parameters of the system.

- A graphics terminal that serves as particle-transport moni or.

- A graphics terminil for displaying intermediate graphics out put.

- A printer for reporting on all phases of system performance.

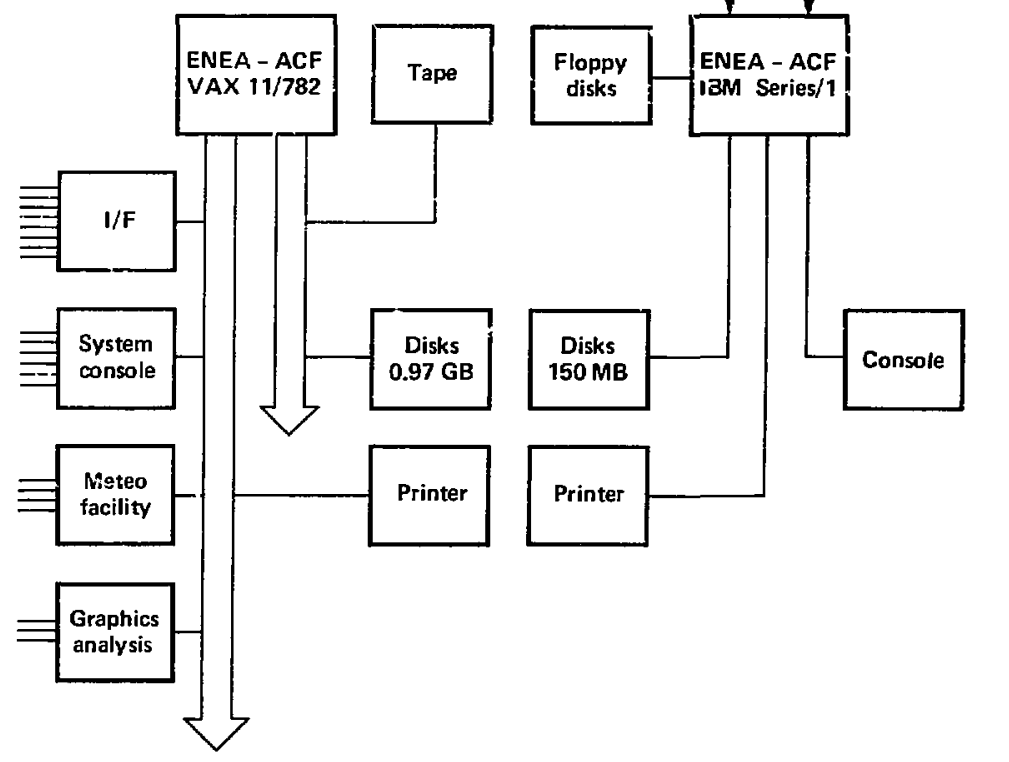

Figure 5. ARIES present hardware configuration. 
At present, all essential meteorological data acquired on the front-end system must be reentered by hand via the ACF input-terminal facility.

\section{Cooperative Studies}

\section{Operational Models}

At present, ARAC has two ADPIC versions on the VAX system. One is the traditional ARAC ADPIC, and the other is the new nested-grid version. ARAC is developing a "model parameters" interface to MEDIC. MATHEW, ADPIC, and PLCNT, which will aid th: assessor in formulating the required model input data. This interface will incorporate default. first-guess, and assessor-defined entries in an interactive, graphically-oriented mode. This interface might be linked with the presaging processing of inputs in the ARIES approach.

\section{System Design and Architecture}

ARAC is currently configured on two multiprocessors (VAX 11/782) clustered with Ethernet/Decnet links to the communications front-end LSI 11/23s. The ARIES ripeline design provides an aiternative approach. These two architectures provide the opportunity to concict benchmark perfornance tests, which could be used to improve both ARIES and ARAC in future system configurations.

\section{Data Retrieval and Decoding}

At present, ARAC and ARIES have complementary meteorological data-processing codes. Exchanges of these codes in the future will benefit both organizations.

\section{Graphical Display}

In the spring of $1984, A R A C$ added a highquality, pseudo-3-dimensional, color, overhead terrain-viewing capability coupled to the terrain data base. Because ARAC and ARIES have identical computer and graphic devices and ARJES can prepare the same input file of terrain data, this new software can be shared with ARIES.

\section{Problem Monitor}

As the ARAC and ARIES systems have evolved to more automated modes, eacl: system has begun to develop problem-monitoring systenis. Such systems keep the assessment staff updated on calculations, essential data, communıcations, and system resources (e.g., available disk space, memory, and CPLs.). ARIES has developed an informative, real-time, model status presentation that ARAC is evaluating for possible incorporation. The entire area of information processiny and feedback is an appropriate candidate for unutual investigation and cooperation.

\section{Future Cooperation}

\section{Model Research}

Through both independent and cooperative research and development during the next several years, the ARAC and ARIES project staff members plan to continue to advance the state of the art of emergency response systems. Future joint ENEA/LLNL work in model research will address the following subjects:

- Decoupling the prescription of vertical and horizontal source-particle diffusion parameters in ADPIC. Based on the iviontalto seabreeze data and on general physical considera- tions, decoupling of vertical and horizontal stability will lead to improved model estimates of concentration patterns and maximum corcentration values.

- Continuing model evaluation studies, particularly for diffusion experiments in complex terrain. The next field data used for model validation will be ASCOT (LLNL) and Brasimone (ENEA) data. Brasimone is a site of complex terrain in the Appennine mountains where METEO-diffusive experiments were performed in September 1984 and June 1985. The ASCOT data base was established with field 
studies in Brush Creek, an arca of complex terrain in western Colorado.

- Installing the plume-rise module in the LLNL ADPIC code and testing the resulting calculations against diffusion experiments that include plume-rise effects.

- Improving the prescription of the MEDIC vertical wind profile when no upperair data are available.

- Addressing several aspects of the SPADE model, such as improving interpolated wind fields from three meteorological stations to extend the spatial range of validity, improving time resolution of wind data with interpolated wind fields at each time step, decoupling of vertical and horizontal stability, and selecting different expressions for diffusion coefficient.

- Investigating diffusion in calm conditions. At present, diffusion in calm coriditions is included in the models as a physical parameter obtained from wind conditions. This circumstance is mainly due to the lack of experimental tracer data in calnı conditions.

- Performing feasibility st udies for release of heavier-than-air toxic chemicals. In terms of model development, this study will address the possibility of combining a 2-dimensiona:, heavier-then-air mode] that would treat the first stage of the diffusion with ADPIC and would cover diffusion after the gas had mixed sufficiently with air.

\section{System Software}

\section{Operational Models}

Providing timely calculations requires streamling and optimizing of the model's environment. For the MATHEW/ADPIC/PLCNT suite of models, graphics elements will be separated from calculational elements. Each element will then be code-optimized for improved throughput performance. At the same time, the primary calculational arrays will be placed in shared, global sections so that graphics processing can proceed on one VAX $11 / 782 \mathrm{CPU}$ while calculational processing continues simultaneously in the second CPU.

\section{System Architecture}

At present, it is difficult to obtain full use of all CPUs in the LLNL dual-VAX 11/782 environment. ARAC will review the current architecture with respect to more loosely coupled, separate CPUis (11/780s or $785 \mathrm{~s})$ with some shared memory bank. The DEC VAXcluster technology is proving to be a strong alternative to the $11 / 782$ master/slave architecture; however, some impacts on the nonmodel portion. of the new ARAC scitware will occur if a change is made in architecture. Alterations to the system architecture wi:. be postponed until an impact assessment is completed.

\section{Meteorological Data Decoders}

ARAC presently uses one U.S. Airways decoder and one WMO upper-air decoder. We look forward to exchanging the latter with ARIES for their synoptic data decode.. The exchange will increase the capabilities of both organizations.

\section{Graphical Display}

ARIES and ARAC share similar graphics workstations (Tektronix 4115); hence, it is possible to share display software. The difficulties with graphics stem from differences in libraries, but these faciors should not be limiting. ARAC will deliver a pseudo-3-dimensional terrain display package to interiace with the ARIES terrain data system early in 1986.

\section{Communications}

ARAC presently has corimunications modems on the VAX that permit 30? and 1200-baud terminal connections and 4800baud DECNET node definition. Durirg 1986, ARAC will conduct feasibility studies to find the best connection. node for the exchange of ARAC and ARIES system improvements. If a DECNET node is used, models can easily be jointly activated and tested. The potential for mutual assistance will then be greatly enhanced.

\section{Hardware}

In the near future, ARAC does not envision major hardware changes beyond those requized for a shift to the loosely-coupled architecture. More disk storage, laser printer, and plotter devices will be purchased as support funcis become available. 
The main changes in the ARIES hardware configuration will be to the computational components. The DEC VAX $11 / 782$ computer will be divided into two VAX 11/780s with an upgrading of one unit to an $11 / 785$ for improved performance. Furthermore, for the communications front-end functions, a Micro VAX-II will be acquired and connected to the two VAX computers by means of a local network (Ethernet), as shown in Figure 6. The

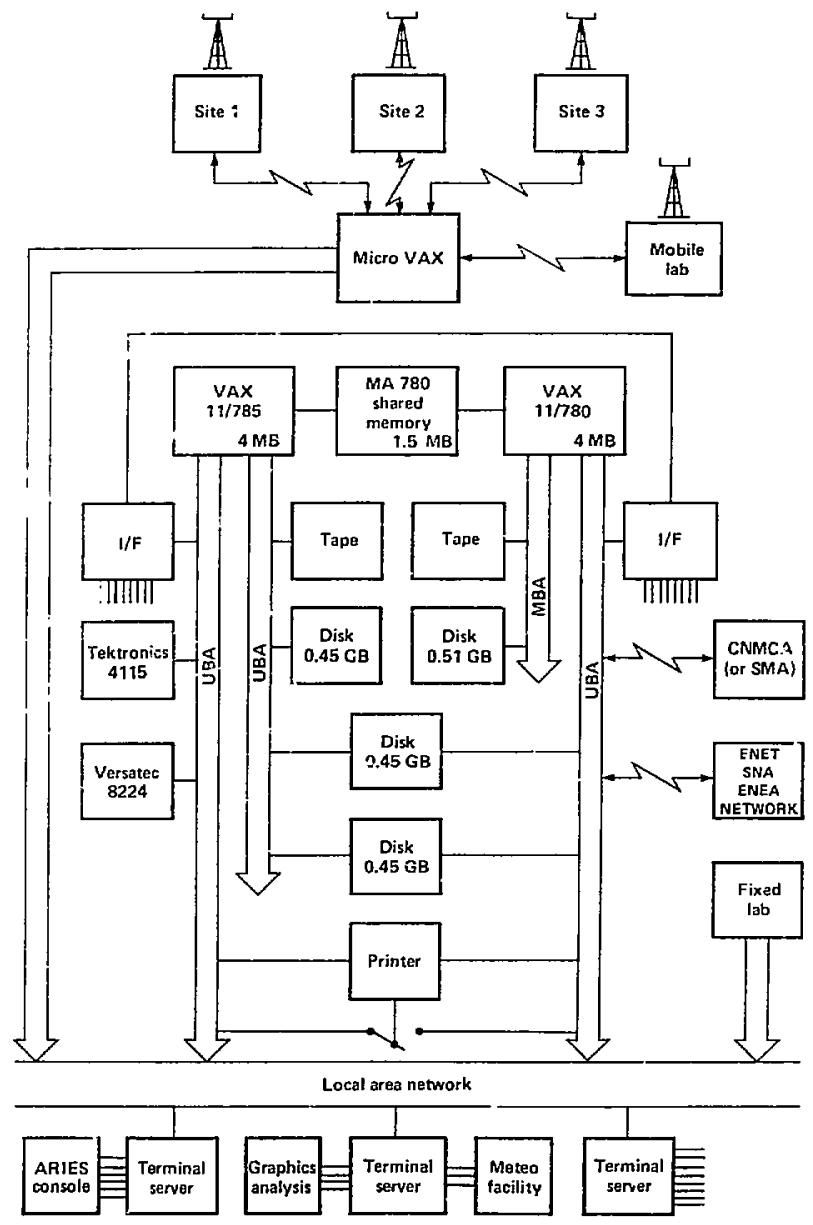

Figure 6. ARIES hardware configuration planned for the future. 
Micro VAX-Il will provide the communications interface to a nuniber of remote sites and a mobile laboratory. The previous data links to the IBM Series 1 front-end computer will be connected directly into the Unibus of the VAX 780 , thus solving the data-transfer problem of the existing configuration (e.g., CNMCA and
ENEA networks). The primary terminals and work stations will be moved from the VAX 782 to a shared configuration on Ethernet. Further improvements will be associated with central memory. mass storage, and peripheral and communications buses.

\section{Recommendations}

The following recommendations are those expected to provide the highest future payoffs. Reconmendations are based on five years of cooperative experience between LLNL and ENEA.

\section{Input/Output Standardization}

At the beginning of cosperation between I.LNL and ENEA, a substantial difference existed in hardware configuration of the ARAC and ARIES systems. This discrepancy required several modifications in the input/output structure of the Italian version of the M/A zcdes. At present boih organizations have similar hardivare components. It is both possible and desirable (in view of future telephone connection of the two central facilities) to standardize the injut/output component. The following items are recommended with respect to standardization:

- Test the M/A codes by means of experimental data collected during field experiments both in the United States and Italy.

- Test and validate with a sample case the upgrade and improvements of the system modules and the introduction of new modules developed by both organizations.

- Execute an exercise or problem from both the ARAC and ARIES systems simultaneously.

\section{Model Development and Evaluation}

Emergency-response systems, such as ARAC and ARIES, are dependent on improved models that are evaluated with fielc experimental data. This area of cooperative research between LLNL and ENEA should continue to recejve high-priority status. Field experiments (e.g., the tracer experiment during calm winds that has been proposed by ENEA) conducted by both organizations should continue to provide dat a to develop better parameterizations for the models and to add to the model evaluation data base. Efforts should centinue toward development of a hydrodynamic assessment model; improvements to the SPADE and $M$ / A models should also be pursued. By working jointly in the area of model development and evaluation, more objective and useful results can be expected for improving and evaluating the emergency-responst models.

\section{Criteria for Emergency-Response Models}

Both ENEA and LL.NL should pool their expertise and experience to develop a set of criteria that enrergency-response models would be expected to meet. Many techniques are available for quantitatively describin wh well models perform against measured airconcentration data obtained from field experiments; however, guidelines should be established for expected performance criteria (EPC) for emergency-response models. Once the EPC have been established, then techniques for evaluatiug models can be suggested. LLNL and ENEA should take the lead in establishing the EPC and then solicit input from other countries and organizations.

\section{Emergency Response for Toxic Chemical Releases}

Both organixations recognize the need for applying emergency-response techniques, learned through planning for nuclear accidents, 
to the toxic chemical industry. The emergencyresponse framework represented by the ARAC and ARIES service can be used as an exceller, $t$ starting point for expansion to other hazardous atmospheric releases. As with nuclear-accident responses, ENEA and LLNL can combine their expertise and experience as a function of each country's needs to develop an improved emergency planning response for the toxic chemical industry. 


\section{References}

1. M. H. Diclierson, P. H. Gudiksen, T. J. Sullivan, and G. D.Greenly, ARAC Status Report: 1985, Lawrence Livermore National Laboratory, Livermore, CA, UCRL-53641 (1985).

2. R. Caracciolo, R. Fiorenza, and A. Guidoni, Centro di Emergenza DISP e Sistema ARIES, ENEA/DISP (in progress).

3. C. A. Sherman, "A Mass-Consistent Model for Wind Fields over Complex Terrain," J. Appl. Meteor. 17, 312.219. (1978).

4. R. Lange, AADPIC--A Three-Dimensional Particle-In-Cell Model for the Dispersal of Atmospheric Pollutants and Its Comparison to Regional Tracer Studies," J. Appl. Meteorol. 17, 320-329 (1978).

5. P. Gudiksen, R. Lange, M. Dickerson, T. Sullivan, L. Rosen, H. Walker, G. B. Boeri, R. Caracciolo, and R. Fiorenza, "Joint Rescarch and Development on Toxic Material Emergency Response between ENEA and Lawrence Livermore National Laboratory: 1982 Progress Report," Lawrence Livermore National Laboratory, Livermore, C A, UCRL-53345 (1982).

6. F. Desiato, "SPADE: A Real-Time i.agrangian-Puff Model for Local Scale Atmospheric Diffusion Evaluation," Commission of European Communities Workshop on Real-time Computing of the Environmental Consequences of an Accidental Release to the Atmosphere from a Nuclear Installation, Luxembourg, September 17-20, 1985.

7. F. Desiato and R. Lange, Introduction of Plume Rise Capability into the Transport and Diffu sion Codes of the ARJES/ARAC Emergency Response Systems, Lawrence Livermore National Laboratory, Livermore. CA (in progress).

8. G. Boeri, R. Caracciolo, and M. H. Dickerson, Real-Time Computing of the Environmental Consequences of an Atmospheric Accidental Releuse of Radioactive Material: User's Poinl of View, Lawrence Livermore National Laboratory, Livermore, CA, UCRL-93116 (1985).

9. F. Desiato and R. Lange, "A Sea-Breeze Tracer Study with the MATHEW/ADPIC Transport and Diffusion Model," IAEA-SM-280/A2, International Atomic Energy Symposium on Emergency Planning and Preparedness for Nuclear Facilities, Rome, Italy, November 4-8, 1985.

10. R. Lange, Relationship Between Model Complexty and Dala Base Quality for Complex Terrain Tracer Experimienti, Ph.D. dissertation. Lawrence Livermore National Laboratory, Livermore, CA (in progress).

11. D. J. Rodriguez and L. C. Rosen, An Evaluation of a Series of $S F_{6}$ Tracer Releases Using the $M A T H E W / A D P I C$ Model, Lawrence Livermore National Laboratory, Livermore, CA, UCRL$91854(19,84)$.

12. K. R. Peterson, and R. Lange, An Evaluation and Sensitivity Study of the MATHEW/ADPJC Models Using EPRI Plains Site Data for a Tall Stack, Lawrence Livermore National Laboratory, Livermore, CA, UCRL-91856 (1984).

13. M. H. Dickerson, Summory of MATHEW/ADPIC Model Evaluation Studies, Lawrence Livermore National Laboratory, Livermore, CA, UCRL-92319 (1985).

14. R. Lange and L. O. Myrup, Relationship between Model Complexity and Data Base Quality for Complex Terrain Tracer Experiments, Lawrence Livermore National Laboratory, Livermore, CA, URCL-90747 (1984).

15. H. Walker, Spatial Dato Requirements for Emergency Response, Lawrence Livermore National Laboratory, Livermore, CA, UCRL 91263 (1985).

16. R. D. Belles, Generating Color Terrain Images in an Emergency Response System, Lawrence Livermore National Laboratory, Livermore, CA, UCRL-92361 (1985).

17. F. Serduke, Lawrence Livermore National Laboratory, Livermore, $\mathrm{CA}$, private communication (1978). 
18. T. V. Crawford, A Computer Frogrnm for Calculating the Atmospheric Dispersion of Large Clouds, Lawrence Livermore National Laboratory, Livermore, CA, URCL-50179 (1966).

19. R. Lange, PATRIC: A Three Dimensional Particle-In-Cell Sequential Puff Code for Modeling the Transport and Diffusion of Atmospheric Pollutants, Lawrence Livermore National Laboratory, Livermore, CA, UCID-17701 (1978). 


\section{Glossary}

Acronyms, Symbols, and Keywords

ADPIC Atmospheric dispersion, particle-in-cell model. A 3-dimensional computer model for the discersion of atmospheric pollutants (LLNL).

AFC ARIES Central Facility.

AFGWC Air Force Global Weather Central (U.S.).

AMS

American Meteorological Society.

ARAC Atmospheric Release Advisory Capability (U.S.).

ARJES

Accidental Release Impact Evaluation System (laly). The main computer programs used by ARIES are METEO, MEDIC, MATHEW, and ADPIC.

ASCOT DOE Atmospheric Studies in Complex Terrain (U.S.).

CALCOMP Graphics sultware package used to obtain color displays for ARIES.

CCR Euratom (Ispra. Italy) Centro Comune di Ricera.

CNMCA Centro Nazionale di Meteorologica e Climatologica dell'Aeronautica. Italian

Weather Center, also referred to as SMA.

DJCMP DEC proprictary communjcalions protocol incorporated in the ARAC

communications syst nm that transfers messages and files between the ARAC central computers and remote site computers.

DECNET DEC cornmunications networking soft ware system.

DEC VAX Digital Equipment Corporation muitiprocessor computer system.

DOD Department of Defense (U.S.).

DOE Department of Energy (U.S.).

ECC Emergency Coorvination Center (Italy).

DISP Direzione Sicurezza e Protezione Sanitaria (Italy). The Directorate for Nuclear

Salety and Health Protection.

EPC Expected performance criteria. L'sed as guidelines that emergency-response models should meet.

EPRI Electric Power Research Institute (U.S.).

ESA European Space Agency.

Ethernet DEC proprietary product that serves as a local area network for ARAC.

FAA Federal Aviation Administration (U.S.).

Handar Microprocessor and data logger.

IAEA International Atomic Energy Agency.

IGL-TEK Interactive Graphics Library (Tektronix Corp.) software used to obtain color displays for ARIES.

KDFOC2 ARAC computer model for assessment of radioactive fallout.

$K_{2}$ Vertical diffusion coefficient.

LLNL

Lawrence Livermore National Laboratory, Livermore, California.

1/A MATHEW/ADPiC eniergency-response model developed at LLNL.

MATHEW Mass-adjusted, three-dimensional, wind-field model (LLNL developed). One of the four main computer programs used by ARAC and ARIES.

MATS Mesoscale Atmospheric Transport Studies.

MBA DEC computer component-MASSBUS adapter.

MEDIC Met:orological data-interpolation code that initializes MATHEW.

METAR An international meteorological data code. This form is used for reporting surface weather conditions.

METEO One of the four main computer software programs used by ARIES. METEO 
soft wart enables the user to select site- and time-specific meteorological data required for an accident or emergency.

Meteosat 2 ESA meteorological satellite. ARIES receives Meteosat 2 cloud imagery via a special communications link.

MINVF Input data file for MATHEW specifying the number of MEDIC wind fields to be processed.

NRC Nuclear P.egulatory Commission (U.S.).

PATRIC Computer model derived from ADPIC and adapted to hemispheric-scale wind fields to calculate intercontinental trensport and diffusion of material.

PJCIN Input file for ADPIC model.

P!CIN1 Input file for ADPIC : sodel that can be read at time ntervals different from those of the wind fields.

PILOT An international meteorological data code. This form is used for reporting upper-atmospheric wind speed and direction from balloon-borne measurement systems.

PI,CNT Plot contours. This plotting code is used for ADPIC input.

SMA Servizio Meterologien dell'Aeronautica. The Italian Air Force Weather Service, also referred to as CNMCA.

SPADE Sequential Puff for Atmospheric Diffusion Evaluation. A three-dimensional, real-time, Lagrangian-puff model for evaluation of atmospheric difiusion.

SYNOP An international meteorological data code. This form is used for reportiag surface weather conditions.

TEMP An international meteorological data code. This form is used for reporting

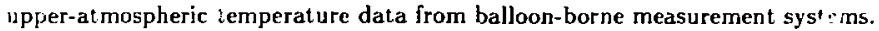

TOPIN Input data file for ADPJC specifying terrain data and grid relationships.

$U$. Friction velocity.

UBA DES computer component-UNIBUS adapter.

USGS U.S. Geological Survey.

UTM Universal Transverse Mercator coordinate s! stem.

WINDY Input file for MATHEW model that specifies observed vind data.

WMO World Meteorological Organization. 